\title{
ALBUMIN-HEPARIN MICROSPHERES AS CARRIERS FOR CYTOSTATIC AGENTS*
}

\author{
H.F.M. Cremers, J. Feijen \\ Department of Chemical Technology, University of Twente, P.O. Box 217, 7500 AE Enschede (The Netherlands)
}

G. Kwon, Y.H. Bae, S.W. Kim

Department of Pharmaceutics, University of Utah, Salt Lake City, UT 84112 (U.S.A.)

\section{H.P.J.M. Noteborn and J.G. McVie}

Department of Experimental Therapy, Netherlands Cancer Institute, Plesmanlaan 121, 1066 CX Amsterdam (The Netherlands)

Key words: microspheres; adriamycin; albumin-heparin conjugate; ion-exchange hydrogels; chemoembolization

\begin{abstract}
Much work has been done on adriamycin-loaded albumin microspheres (Alb-MS) for chemoembolization [1-4], the rationale being that site-specific drug delivery may increase the therapeutic efficacy of the drug. Alb-Ms are being investigated because of their biocompatibility and because the degradation products of these microspheres are non-toxic. However, these microspheres have some disadvantages (i.e. drug loading during the microsphere preparation, low payloads, large burst effects). These disadvantages can be overcome by the incorporation of heparin (a highly negatively charged mucopolysaccharide). Albumin-heparin microspheres were prepared (i) by crosslinking of soluble albumin and heparin first using 1-ethyl-3-(3-dimethylaminopropyl)carbodiimide (EDC) and subsequently glutaraldehyde (Alb-Hep-MS) and (ii) by crosslinking a preformed soluble conjugate of heparin and albumin with glutaraldehyde (Alb-Hep-Conj-MS). Albumin-heparin microspheres could be loaded with adriamycin after microsphere preparation giving payloads of $15-30 \%$. Preliminary in vitro adriamycin release experiments showed that AlbHep-Conj-MS exhibit sustained release properties. Furthermore ion-exchange properties could be observed both with Alb-Hep-MS and Alb-Hep-Conj-MS. In vitro and in vivo toxicity experiments with Alb-Hep-MS showed no adverse effects.
\end{abstract}

\section{INTRODUCTION}

Since albumin microspheres (Alb-MS) were first described as possible drug delivery devices [5], many different types of drugs (i.e. peptides $[6]$, steroids $[7,8]$ and low molecular weight, water-soluble compounds [9] have been incorporated. Among the drugs incorporated, cyto-

*Paper presented at the Fourth International Symposium on Recent Advances in Drug Delivery Systems, Salt Lake City, UT, U.S.A., February 21-24, 1989. static agents (i.e. mercaptopurine [5], 5-fluorouracil [8], mitomycin C [10], and adriamycin [1-4]) take an important place.

In the past much work has been done on the preparation and application of adriamycin loaded albumin microspheres (Adx-Alb-MS) $[1,3,4]$. Adriamycin is an anthracycline antibiotic which is widely used in cancer chemotherapy. This cytostatic agent however, exerts high cardiotoxicity upon intravenous bolus injection, which is a major drawback in the appli- 
cation of this drug. This may be overcome by the incorporation of the drug in microparticulate carriers (e.g. Alb-MS), which can be used for chemoembolization. Chemoembolization refers to the intra-arterial coadministration of drugs and vascular occlusive devices to treat cancer. The rationale is that the administration of drug loaded particles of the requisite size (15-60 $\mu \mathrm{m}$ ) either causes tumour infarction by occlusion or induces transient ischemia within the tumour vasculature, whereupon the entrapped drug can be released locally. Moreover, tissue permeability is increased due to anoxia, allowing the drug to permeate into the tissue more easily [11].

In general Adx-Alb-MS are prepared as follows. An aqueous solution of albumin which also contains adriamycin is added to an organic phase (i.e. olive oil, cottonseed oil, or a mixture of cottonseed oil with petroleum ether). A water-in-oil emulsion is being formed by mechanical stirring or by sonification. Stabilization of the Adx-Alb-MS is then carried out either by heat stabilization or by chemical crosslinking using gluraraldehyde, formaldehyde or 2,3-butadione as crosslinking agents $[1,3,4]$.

The use of Adx-Alb-MS for the release of adriamycin has some drawbacks. The preparation methods afford only low payloads (1-10\%). Furthermore, adriamycin may react with the crosslinker during the stabilization process. Adriamycin may also decompose when the microspheres are stabilized at high temperatures. The microspheres prepared are somewhat hydrophobic and surfactants are needed to resuspend them in aqueous solutions. Another problem is the large burst effect usually observed with Adx-Alb-MS.

Longo and Goldberg have developed a method to prepare hydrophilic albumin microspheres [2]. A concentrated solution of high molecular weight polymer in an organic solvent instead of oil was used as the hydrophobic (organic) phase. Glutaraldehyde is dissolved in the organic phase and reacts mainly at the surface of the Alb-MS, yielding a relatively high surface concentration of unreacted aldehyde groups. In this way relatively hydrophilic microspheres are obtained. The authors claim that these microspheres can be loaded with adriamycin after the preparation and that payloads of about $18 \%$ can be reached.

In general the in vitro release of adriamycin from these monolithic albumin microspheres is considered to be biphasic. An initial large and fast release (i.e. the burst effect), is followed by a much slower, first-order release [12]. During the first phase a large amount of the drug may be released within a few minutes to hours. Some authors, however, propose triphasic zero-order kinetics $[13,14]$.

Some of the disadvantages mentioned above may be overcome by incorporating negatively charged polymers into the albumin microspheres. Longo et al. [15] used a combination of poly ( $\alpha$-L-glutamic acid) and albumin in their microspheres. Adriamycin loading after preparation gave surprisingly high payloads up to $40 \%$ and more (instead of $16 \%$ for unmodified albumin microspheres). Willmott et al. [16] modified albumin microspheres by the addition of poly ( $\beta$-L-aspartic acid). Drug loading during the preparation process resulted in a payload of $4 \%$ ( $1 \%$ for unmodified albumin microspheres).

In order to obtain improved carriers for the delivery of cytostatic agents, we have prepared microspheres which are made from albumin and heparin (Alb-Hep-MS). These microspheres have been synthesized by techniques similar to the preparation of albumin microspheres either starting with an aqueous mixture of albumin and heparin followed by stabilization with 1ethyl-3-(3-dimethylaminopropyl)carbodiimide (EDC) and glutaraldehyde, respectively, or by use of preformed soluble albumin-heparin conjugates [17], which are stabilized with glutaraldehyde. In this way hydrophilic, biodegradable microspheres composed of endogenous materials are obtained. Heparin is highly negatively charged at physiological conditions 
due to carboxylic acid, sulphate and sulphamate groups. Thus strong ionic interactions with positively charged drugs like adriamycin are possible [18]. This also may provide high payloads for such drugs and prolong the release. The loading of the microspheres can be carried out after the microspheres have been prepared. In principle Alb-Hep-MS can also be loaded with other drugs of higher molecular weight by a swelling-deswelling process. The preparation, characterization and release properties of Alb-Hep-MS loaded with adriamycin will be discussed in this paper. The results are compared with these obtained with Alb-MS.

\section{MATERIALS AND METHODS}

\section{Reagents}

Human serum albumin was obtained from the Central Laboratory of the Dutch Red Cross Blood Transfusion Service, Amsterdam, The Netherlands. Heparin from porcine intestinal mucosa was obtained from Diosynth, Oss, The Netherlands. Two different batches were used, both with a specific activity of $165 \mathrm{IU} / \mathrm{mg}$ as indicated by the manufacturers. Cibracon blue sepharose (CBS) and diethylaminoethyl sepharose $4 \mathrm{~B}$ (DEAE) were obtained from Pharmacia Fine Chemicals, Uppsala, Sweden. EDC used in microsphere preparation (double crosslinking technique) and highly refined olive oil were both obtained from Sigma Chemical Company, St. Louis, MO, U.S.A. EDC used for the conjugate synthesis, glutaraldehyde $(25 \%$ aqueous solution), and the solvents and other chemicals used, were all obtained from MerckSchuchardt, Hohenbrunn, West-Germany. Adriamycin was a kind gift from Prof. Dr. F. Arcamone, Farmitalia, Milan, Italy. Polycarbonate membrane filters $(8 \mu \mathrm{m})$ were obtained from Nuclepore, Pleasanton, USA. $\mathrm{BD}_{2} \mathrm{~F}_{1}$ mice and WAG/Rij rats, bred under SPF conditions, were obtained from the Animal Department of the Netherlands Cancer Institute, Amsterdam, The Netherlands.
Synthesis, purification and characterization of soluble conjugates of albumin and heparin

The synthesis of the albumin-heparin conjugate was carried out by the slightly modified method of Hennink et al. [17]. Albumin (12.5 g) and heparin ( $3.75 \mathrm{~g}$ ) were dissolved in 175 $\mathrm{ml}$ of water. This solution was adjusted to $\mathrm{pH}$ 5.0 with $\mathrm{HCl}(0.2 \mathrm{M})$. During the addition of $\mathrm{HCl}$, a precipitate was formed. This precipitate dissolved almost completely within 45 minutes. A solution of $1.24 \mathrm{~g} \mathrm{EDC}$ was added dropwise to the reaction mixture over a period of 4 hours at room temperature. Thirty minutes after the addition of EDC, the $\mathrm{pH}$ was adjusted to 7.6 with $\mathrm{NaOH}(1 M)$ and the mixture was gently stirred for $20 \mathrm{~h}$ at $4^{\circ} \mathrm{C}$. Finally the solution was dialyzed twice against $0.025 M$ Tris- $\mathrm{HCl}$ buffer, $\mathrm{pH}$ 7.5.

Unreacted heparin and albumin were separated from the albumin-heparin conjugate with chromatographic procedures, using a CBS column and a DEAE column, respectively.

The heparin content of the conjugate was determined with the slightly modified colorimetric method using Azure $A$ as described by Jacques and Wollin [19]. The albumin content was determined using two methods, by UV/Vis spectroscopy at $280 \mathrm{~nm}$, and by a modified biuret-method [20].

\section{Microsphere preparation}

Albumin microspheres (Alb-MS) were prepared as described by Tomlinson et al. [12]. In a typical experiment $125 \mathrm{ml}$ of highly refined olive oil was prestirred $(850 \mathrm{rpm})$ in a baffled cell at room temperature for at least $30 \mathrm{~min}$ utes. To this oil $0.4 \mathrm{ml}$ of an albumin solution (150 mg dissolved in $0.6 \mathrm{ml}$ isotonic buffer $\mathrm{pH}$ 7.4) was added dropwise from a syringe. The resulting water-in-oil emulsion was stirred for 15 minutes. Then $0.1 \mathrm{ml}$ of an aqueous glutaraldehyde solution $(25 \% \mathrm{w} / \mathrm{v})$ was added. After $1 \mathrm{~h}$ stirring, $55 \mathrm{ml}$ of acetone was added and stirring was continued for 1 minute. The micro- 
spheres were isolated by centrifugation for 15 minutes at $2000 \mathrm{rpm}$, followed by decanting of the supernatant. After resuspending the microspheres in acetone and collecting them on a 8 $\mu \mathrm{m}$ polycarbonate membrane filter, they were washed and dehydrated with acetone. In the case of adriamycin-loaded albumin microspheres (Adx-Alb-MS) the adriamycin was added to the albumin solution before emulsification.

Albumin-heparin microspheres made from the soluble conjugate (Alb-Hep-Conj-MS) were prepared in a similar way as the Alb-MS. Since the conjugate solution was more viscous, a higher stirring speed (1230 rpm) was required to obtaine microspheres with a similar size as Alb-MS. The crosslinking time after glutaraldehyde addition was 3.5 hours.

Albumin-heparin microspheres (Alb-HepMS) were also prepared from free albumin and heparin, using a double crosslinking technique. A solution $(0.4 \mathrm{ml})$ of $100 \mathrm{mg}$ of albumin and $50 \mathrm{mg}$ of heparin in $0.6 \mathrm{ml}$ water was added dropwise to prestirred ( $850 \mathrm{rpm}$ ) olive oil. After emulsification for 15 minutes, $0.1 \mathrm{ml}$ of EDC solution ( $30 \mathrm{mg}$ EDC in $0.15 \mathrm{ml}$ water) was added. After stirring for $4 \mathrm{~h}, 0.1 \mathrm{ml}$ of an aqueous glutaraldehyde solution $(25 \% \mathrm{w} / \mathrm{v})$ was added and the emulsion was stirred for one more hour. Microspheres were collected and washed as described above.

After the preparation, the microspheres were extensively washed to remove unbound material. This washing procedure was carried out as follows. The microspheres (about $100 \mathrm{mg}$ ) were ultrasonically resuspended in $5 \mathrm{ml}$ ethanol. To this suspension $45 \mathrm{ml}$ of a $4 \mathrm{M} \mathrm{NaCl}$ solution was added and the microspheres were gently rotated overnight at $25^{\circ} \mathrm{C}$. The microspheres were then isolated by centrifugation (15 minutes, $2600 \mathrm{rpm}$ ) and the supernatant was decanted. The microspheres were once more resuspended in $50 \mathrm{ml} 4 M \mathrm{MaCl}$ solution and rotated for 30 minutes. After centrifugation, this was repeated once with a $2 \mathrm{M} \mathrm{NaCl}$ solution and twice with water. The microspheres were then col- lected on a $8 \mu \mathrm{m}$ polycarbonate membrane filter and dehydrated with acetone.

\section{Particle size of the microspheres}

The determination of the size and the size distribution of the microspheres was carried out using scanning electron microscopy and by using a light microscope fitted with a calibrated graticule. The SEM micrographs were analyzed using a particle size analyzer (Carl-Zeiss TG3).

\section{Quenching of the microspheres}

Because the microspheres were crosslinked with glutaraldehyde, some unreacted aldehyde groups may be left in the matrix. To prevent covalent coupling of the adriamycin via its amine group to these aldehyde groups, microspheres were quenched with glycine. Dry microspheres $(10 \mathrm{mg})$ were ultrasonically resuspended in $0.5 \mathrm{ml}$ of ethanol, after which 0.5 $\mathrm{ml}$ of water was added. This suspension was centrifuged for 15 minutes at $2000 \mathrm{rpm}$ and the supernatant was decanted. To the hydrated microspheres was added $1 \mathrm{ml}$ of a $10 \mathrm{w} / \mathrm{v} \%$ glycine solution in water. This suspension was gently rotated for $20 \mathrm{~h}$ at $25^{\circ} \mathrm{C}$. The suspension was then centrifuged for 15 minutes at 2000 $\mathrm{rpm}$, the glycine solution was decanted and the quenched microspheres were washed with water and dehydrated with acetone.

\section{Drug loading}

The microspheres (except for the Adx-AlbMS) were loaded after preparation. In a typical experiment, $10 \mathrm{mg}$ of microspheres were ultrasonically suspended in $0.5 \mathrm{ml}$ of ethanol and 0.5 $\mathrm{ml}$ of water was added. After centrifugation (15 minutes, $2000 \mathrm{rpm}$ ) and decanting of the supernatant, $1 \mathrm{ml}$ of adriamycin solution $(10 \mathrm{mg}$ / $\mathrm{ml}$ water) was added. This suspension was gently rotated for $20 \mathrm{~h}$, at $4^{\circ} \mathrm{C}$, blocking light. After collection of the microspheres, they were washed four times with $1 \mathrm{ml}$ of water. The rins- 
ing water containing unbound adriamycin was carefully collected. After washing the microspheres were dehydrated with acetone.

\section{Payload determination}

Payloads (\% w/w) were calculated from the adriamycin depletion of the loading solution and the adriamycin content in the rinsing water. These were determined by UV/Vis spectroscopy at $494 \mathrm{~nm}$.

\section{In vitro release experiments}

For the in vitro release experiments two systems (a batch system and a flow system) were used. In the batch system $5 \mathrm{mg}$ of microspheres, ultrasonically suspended in 0.5 ethanol, were added to $50 \mathrm{ml}$ release medium (double distilled water, or isotonic buffer $\mathrm{pH} 7.4$ containing $0.1 \%$ $\mathrm{v} / \mathrm{v}$ Tween 80 ), pre-equilibrated at $37^{\circ} \mathrm{C}$ in 300 $\mathrm{ml}$ bottles in a shaking bath. At different time intervals, the suspension was homogenized and $1.5 \mathrm{ml}$ samples were taken. These were centrifuged for 5 minutes at $1000 \mathrm{rpm}$. The adriamycin content from the supernatant was determined with UV/Vis spectroscopy at $494 \mathrm{~nm}$.

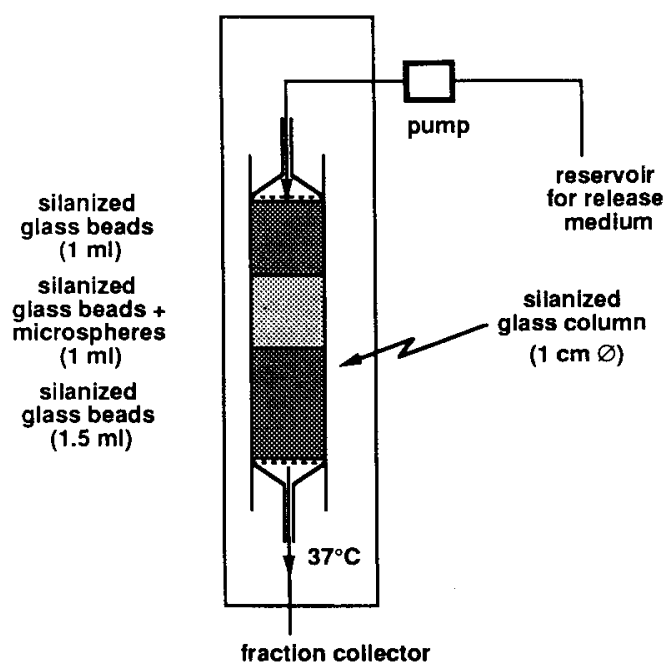

Fig. 1. Flow system for in vitro adriamycin release from microspheres.
In the flow system (Fig. 1), a glass column $(\varnothing=1 \mathrm{~cm})$ was filled with glass beads $(1.5 \mathrm{ml}$, first layer ), glass beads $(1 \mathrm{ml}$ ) mixed with $5 \mathrm{mg}$ of dry, loaded Alb-Hep-Conj-MS (second layer) and $1 \mathrm{ml}$ of glass beads again (third layer). The system was equilibrated at $37^{\circ} \mathrm{C}$. The flow rate was controlled at $13.6 \mathrm{ml} / \mathrm{min}$. The release medium was isotonic buffer, $\mathrm{pH}$ 7.5. The adriamycin content from the eluted buffer was determined with UV/Vis spectroscopy at $494 \mathrm{~nm}$.

\section{In vitro toxicity of the Alb-Hep-MS}

The in vitro toxicity of the albumin-heparin microspheres obtained via the double crosslinking technique was studied using a colony formation assay. Cultured B16 melanotic melanoma cells ( \pm 75 per well) were incubated for 6 days with $3 \mathrm{ml}$ of a microsphere suspension (varying from $0.001 \mathrm{mg} / \mathrm{ml}$ to $10 \mathrm{mg} / \mathrm{ml} ; n=6$; control: $n=10$ ). After 7 days the cells in the different wells were counted.

\section{In vivo toxicity of the Alb-Hep-MS}

The in vivo toxicity of the albumin-heparin microspheres obtained via the double crosslinking technique was determined by IP administration of microspheres into $\mathrm{BD}_{2} \mathrm{~F}_{1}$ mice. The microspheres were ultrasonically resuspended in ethanol $(75 \% \mathrm{w} / \mathrm{v})$ and sterilized by $30 \mathrm{~min}-$ utes incubation. After centrifugation and decanting of the ethanol, the microspheres were resuspended in $0.9 \% \mathrm{NaCl}$ solution. This suspension was IP injected in different amounts varying from $5.0 \mathrm{mg} / \mathrm{kg}$ to $200 \mathrm{mg} / \mathrm{kg}(n=6)$. In control experiments, a $0.9 \% \mathrm{NaCl}$ solution without microspheres was injected $(n=10)$. The weight of the mice was monitored at different time intervals, being a first indication of the in vivo toxicity of the Alb-Hep-MS.

After an inoculation period of 60 days, the mice were sacrificed for further histological examination of the organs (i.e. liver, spleen, lungs, stomach, kidneys). A general histological stain (hematoxylin and eosin) was used to differen- 
tiate cell types after fixation in $4 \%$ formol (buffered formaline).

\section{In vivo biodegradation of Alb-Hep-MS}

In 12 male WAG/Rij rats (average weight: $300 \mathrm{~g}$ ) a dose of $6.0 \mathrm{mg} \mathrm{Alb}-\mathrm{Hep}-\mathrm{MS} / \mathrm{kg}$ rat was injected via the mesenteric vein into the liver. The same microsphere suspension was prepared as mentioned above. The rats were kept in a temperature-controlled room on a $12 \mathrm{~h}$ light-12 h darkness schedule in a standard rat cage, with tap water ad libitum. The weight of the rats and the level of liver-function marker enzymes was monitored for two weeks. After six weeks the animals were sacrificed for further examination. Liver sections were fixated using $4 \%$ formol and stained with Giemsa-stain.

\section{RESULTS AND DISCUSSION}

The conjugate of albumin and heparin (AlbHep-Conj) was prepared according to Hennink et al. in a yield of about $50 \%$. The conjugate could be further separated in fractions with a low and high affinity for the DEAE column. (G. Engbers and J. Feijen, unpublished results). Table 1 shows the compositions of the two frac-

TABLE 1

Composition of the albumin-heparin conjugates

\begin{tabular}{clll}
\hline & $\begin{array}{l}\text { Heparin } \\
\text { content }^{\mathrm{a}} \\
(\mathrm{w} \%)\end{array}$ & $\begin{array}{l}\text { Albumin } \\
\text { content } \\
(\mathrm{w} \%)\end{array}$ & $\begin{array}{l}\text { Alb/Hep } \\
(\mathrm{mol} / \mathrm{mol})\end{array}$ \\
\hline $\begin{array}{c}\text { Low DEAE } \\
\text { affinity } \\
\text { fraction }\end{array}$ & $10.0 \pm 2.1$ & $92.5 \pm 2.9^{\mathrm{c}}$ & $1.56 \pm 0.47$ \\
$\begin{array}{c}\text { High DEAE } \\
\text { affinity } \\
\text { fraction }\end{array}$ & $10.2 \pm 1.2$ & $92.3 \pm 3.0^{\mathrm{d}}$ & \\
\hline
\end{tabular}

acolorimetric determination using Azure A.

${ }^{b}$ Molecular weights used for this calculation were 66,000 for albumin and 11,000 for heparin.

'Determination using a modified biuret method for protein determination.

${ }^{\mathrm{d}} \mathrm{UV} / \mathrm{V}$ is spectrophotometric determination at $280 \mathrm{~nm}$.
TABLE 2

Results of microsphere preparation

\begin{tabular}{|c|c|c|c|}
\hline & Alb-MS & Alb-Hep-MS & $\begin{array}{l}\text { Alb-Hep-Conj- } \\
\text { MS }\end{array}$ \\
\hline $\begin{array}{l}\text { Stirring speed } \\
(\mathrm{rpm})\end{array}$ & 850 & 850 & 1230 \\
\hline Diameter $(\mu \mathrm{m})$ & $4-25$ & $4-30$ & $12-80$ \\
\hline \multicolumn{4}{|l|}{ Yield } \\
\hline conjugate synth. & - & _ & $50 \%$ \\
\hline ms-preparation & $98 \%$ & $94 \%$ & $90 \%$ \\
\hline washing & $77 \%$ & $50 \%$ & $76 \%$ \\
\hline Appearance & $\begin{array}{l}\text { brown, free- } \\
\text { flowing powder }\end{array}$ & $\begin{array}{l}\text { white, free- } \\
\text { flowing powder }\end{array}$ & $\begin{array}{l}\text { brown, free- } \\
\text { flowing powder }\end{array}$ \\
\hline
\end{tabular}

tions; the high DEAE affinity fraction was used for the preparation of the Alb-Hep-Conj-MS.

The results of the microsphere preparation are shown in Table 2. To obtain Alb-Hep-ConjMS of approximately the same size as Alb-MS and Alb-Hep-MS, a higher stirring speed is required. This is due to the higher viscosity of the Alb-Hep-Conj solution which is used for injection into the oil phase. Figure 2 shows that the Alb-Hep-Conj-MS (2c) are still. larger than the other microspheres $(2 a, 2 b)$, and have a larger size distribution which is also due to the higher viscosity of the aqueous conjugate solution. The sizes of Alb-MS (2a) and Alb-Hep-MS (2b) are comparable, but the latter microspheres show partially collapsed surfaces, which may be due to the extraction of unbound material during the washing steps. The amount of material removed during washing for these Alb-Hep-MS was substantially higher as compared to that for the other microsphere preparations (Table 2 ). The weight loss of the latter preparations is probably only due to the losses during the decantation and collection steps. The surfaces of Alb-Ms and Alb-Hep-Conj-MS were perfectly smooth $(2 \mathrm{a}, 2 \mathrm{c})$.

Since the conjugate with the highest affinity for the DEAE column was used for the Alb-HepConj-MS preparation, the composition of these microspheres is known. It can also be expected that the heparin is homogeneously distributed 

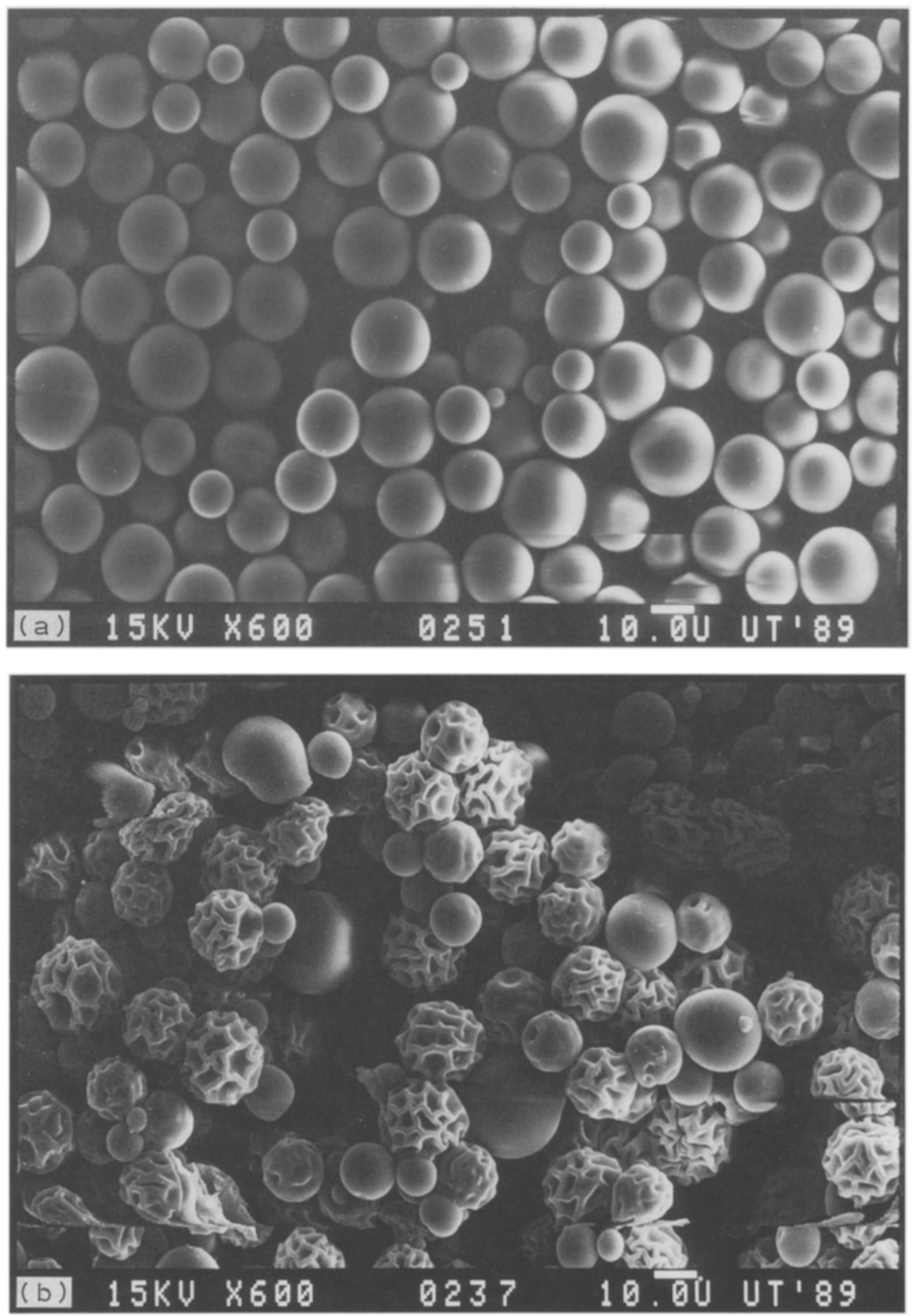

Fig. 2. SEM micrographs from (a) Alb-MS and (b) Alb-Hep-Ms. 


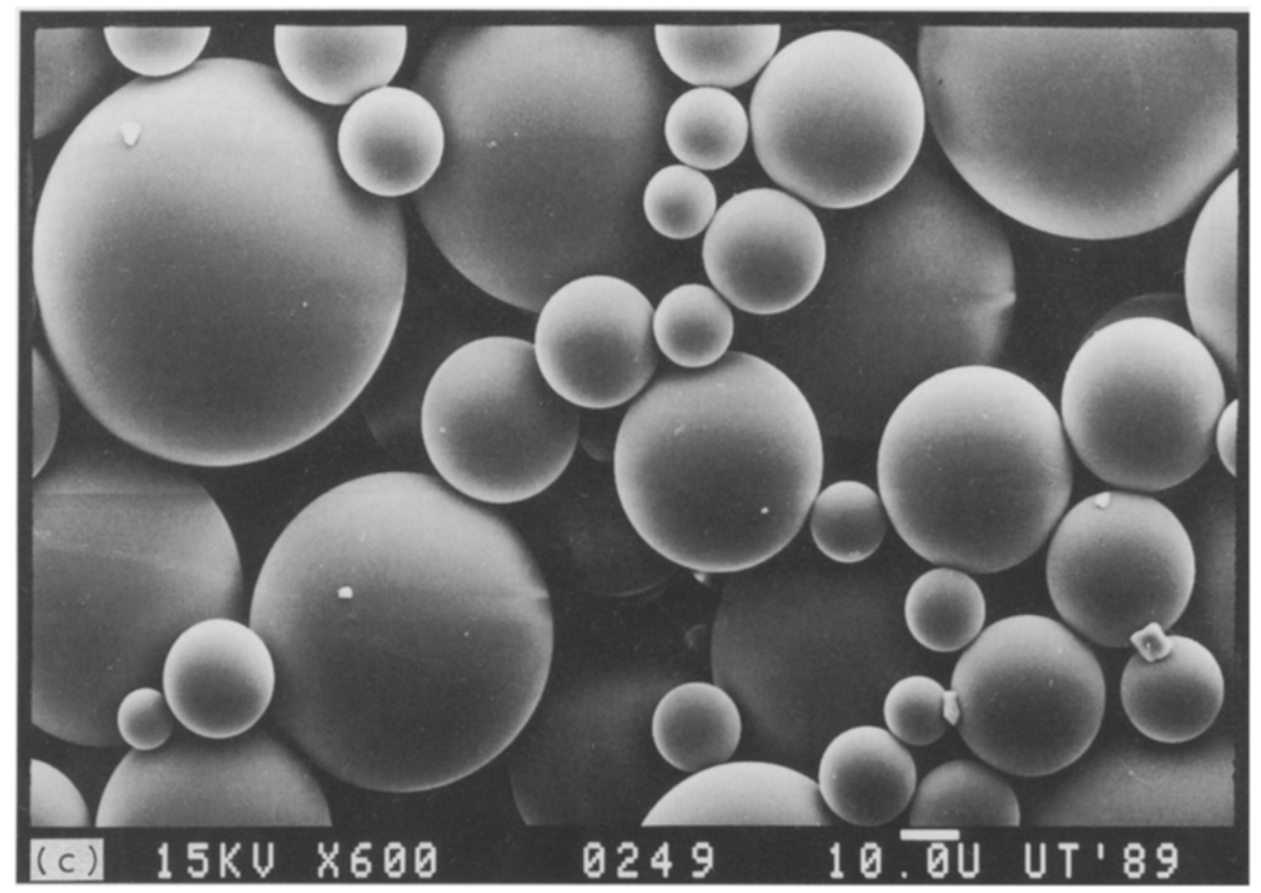

Fig. 2 (continued). SEM micrographs from (c) Alb-Hep-Conj-MS.

throughout the microsphere. The composition of the Alb-Hep-MS is not exactly known. Also it is not known if the heparin or the albumin is located preferentially at the core or at the surface of the droplets in the water-in-oil emulsion. These factors certainly influence the drug loading and drug release properties of the microspheres, and will be further investigated to fully understand the behaviour of these drug release systems.

As can be seen from Table 3, the payloads of

\section{TABLE 3}

Payloads of the microspheres

\begin{tabular}{llll}
\hline Adx-Alb-MS $^{\mathrm{a}}$ & Alb-MS $^{\mathrm{b}}$ & Alb-Hep-MS $^{c}$ & Alb-Hep-Conj-MS $^{\mathbf{d}}$ \\
\hline $8 \%$ & $7 \%$ & $25-30 \%$ & $15-20 \%$ \\
\hline
\end{tabular}

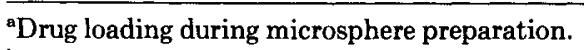

${ }^{b}$ Drug loading after microsphere preparation, rinsing water was coloured up to the fourth washing step.

'Drug loading after microsphere preparation, the microspheres were not rinsed with water after loading.

${ }^{\mathrm{d}}$ Drug loading after microsphere preparation. the Alb-MS and the Adx-Alb-MS were approximately the same. However, HPLC analysis of the drug from the Adx-Alb-MS showed that the major amount consisted of the aglycon-moiety of adriamycin, thus indicating decomposition of the adriamycin during the drug loading pro-

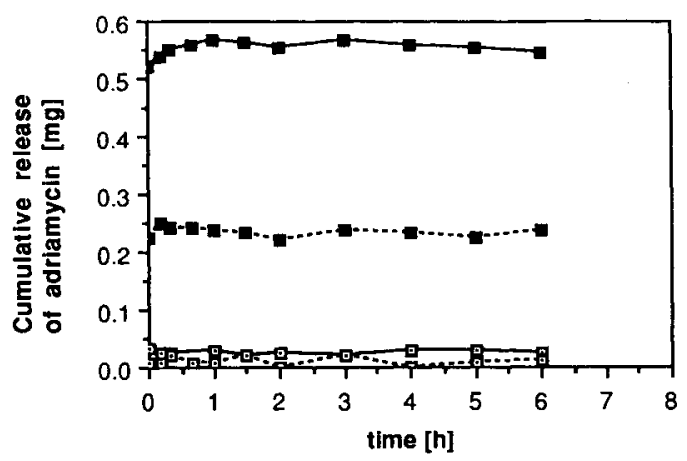

Fig. 3. Adriamycin release from albumin and albumin-heparin microspheres in isotonic buffer, containing $0.1 \% \mathrm{v} / \mathrm{v}$ Tween 80 and in water. Initial amount of adriamycin: AlbHep-MS: $1.2 \mathrm{mg}$; Alb-MS: $0.3 \mathrm{mg}$. -0-: Alb-Hep-MS, buffer; --.-- $\square-$ Alb-Hep-MS, water; $-\square-$ : Alb-MS, buffer; ----- $\square-----$ Alb-MS, water. 
cess. This was not the case with the other microspheres, which were loaded after preparation.

The drug loading of the Alb-Hep-MS and the Alb-Hep-Conj-MS resulted in higher payloads as compared to the Alb-MS. The payload of the Alb-Hep-MS was the highest, but it should be taken into account that these microspheres were not washed with water (to remove free drug) after drug loading. As can be observed from Fig. 3 , adriamycin is released from these microspheres in water. It must be concluded that the payload of these microspheres would have been reduced had these microspheres been treated the same way as the Alb-MS and the Alb-HepConj-MS. In the Alb-Hep-Conj-MS, almost no free drug was present after drug loading, since the water from the washing steps after drug loading was colourless.

From Fig. 3 it can be observed that the adriamycin release from Alb-Hep-MS is influenced by the ionic strength of these release medium. In isotonic buffer, the amount of adriamycin released is almost twice as high as in water. From this it may be concluded that the Alb-Hep-MS exhibit ion-exchange properties. Also, the amount of adriamycin released from the AdxAlb-MS was much lower than the release from the Alb-Hep-MS. Figure 4 shows another ex-

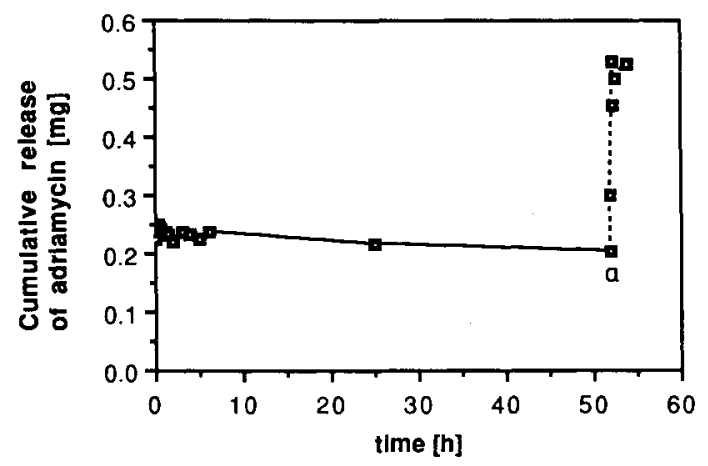

Fig. 4. Adriamycin release from albumin-heparin microspheres, prepared using double crosslinking and loaded after preparation. Release medium: water; at a: addition isotonic buffer, containing $0.1 \% \mathrm{v} / \mathrm{v}$ Tween 80 . Initial amount of adriamycin: $1.2 \mathrm{mg}$. ample of ion-exchange effects. After addition of isotonic buffer to the release medium (water) and thus increasing the ionic strength of the medium, the release of adriamycin is more than doubled. From Fig. 5 can be seen that adriamycin release from the Alb-Hep-Conj-MS is a two-phase process. First there is an initial burst, which is followed by a slower release in the second phase. This can also be observed in Fig. 6: an initial fast release (ca. $23 \%$ release within one hour) followed by a slow release (ca. $8 \%$ release for the next 6 hours). This release pattern is favourable compared with the release

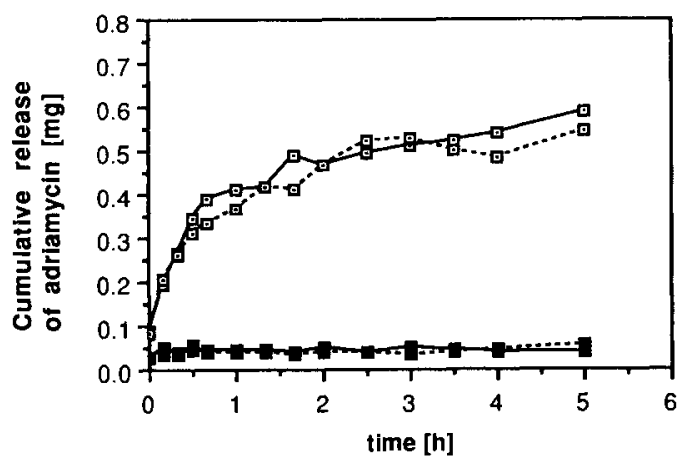

Fig. 5. Adriamycin release from quenched and unquenched albumin and Alb-Hep conjugate microspheres (both loaded after preparation) in isotonic buffer, containing $0.1 \% \mathrm{v} / \mathrm{v}$ Tween 80. Initial amount of adriamycin: Alb-Hep-ConjMS: $1.0 \mathrm{mg}$; Alb-MS: $0.35 \mathrm{mg}$.-- - Alb-MS, unquenched; -...-- - -.-: Alb-MS, quenched; $-\square-$ : Alb-Hep-Conj-MS, unquenched; ------ $\square----$ : Alb-Hep-Conj-MS, quenched.

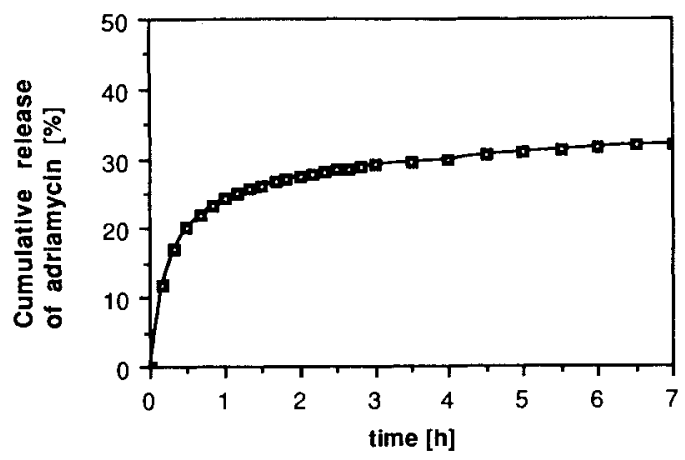

Fig. 6. Adriamycin release from albumin-heparin conjugate microspheres in isotonic buffer, containing $0.1 \% \mathrm{v} / \mathrm{v}$ Tween 80 , using a flow system. 
patterns from Adx-Alb-MS and loaded Alb-MS and Alb-Hep-MS since in these systems, the major amount of adriamycin is released almost instantly. Administration of these adriamycin formulations will resemble a bolus injection. In the case of Alb-Hep-Conj-MS only a relatively small amount of adriamycin is released during the first 15 minutes. This provides sufficient time to inject the microspheres into the target organ applying the principle of chemoembolization.

From the release experiments it can be concluded that the release of adriamycin from the albumin and albumin-heparin matrices depends on the way the drug is present in the matrix (Fig. 7). Part of the adriamycin in the microspheres will be unbound. This free drug will be released in buffer as well as in water and the release rate is controlled by the diffusion of the drug through the albumin-heparin matrix. Another part of the adriamycin has formed an

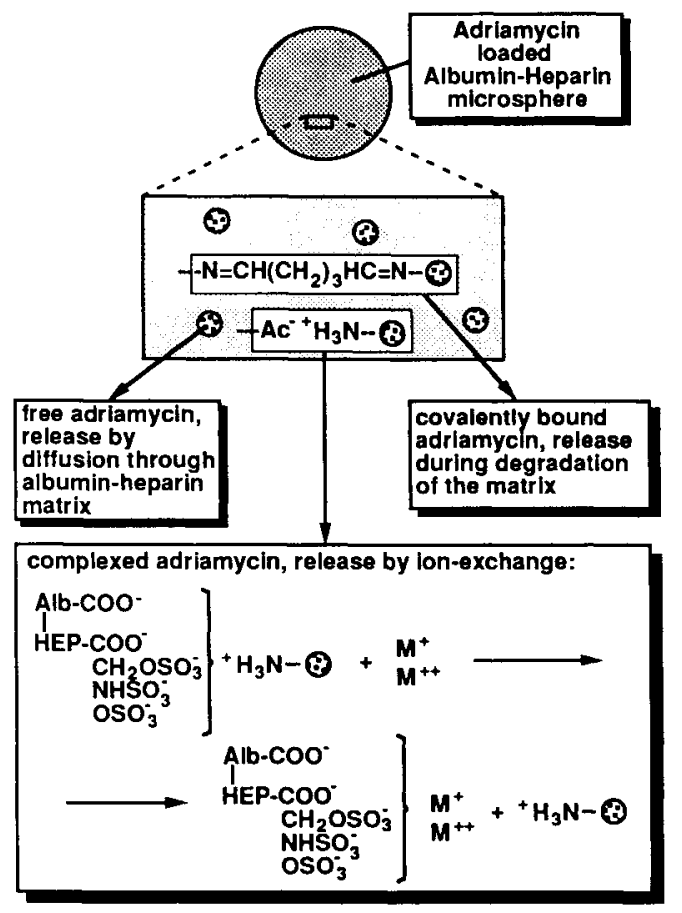

Fig. 7. Mechanisms of adriamycin release from albuminheparin microspheres. ion complex with the negatively charged groups of the matrix, and will only be released if the ionic strength of the release medium is high enough. In Alb-MS and Adx-Alb-MS only a small amount of negatively charged groups is present and although Alb-MS exert some ionexchange properties [21], almost no influence of the ionic strength of the release medium on the adriamycin release can be observed (Figs. 3 and 5). The Alb-Hep-MS and the Alb-HepConj-MS, however, are highly negatively charged (depending on the amount of heparin) and these microspheres clearly show ion-exchange properties (Figs. 3, 4 and 5).

Finally, some of the drug will be covalently

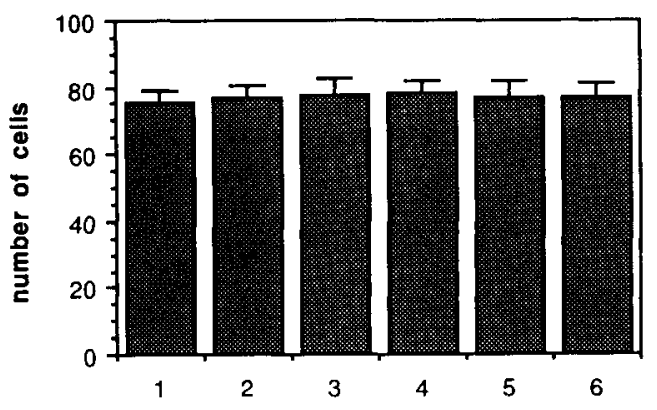

Fig. 8. In vitro toxicity determined by colony formation assay, continuous exposure, during 6 days, of B16 melanotic melanoma cells $( \pm 75)$ to $3 \mathrm{ml} \mathrm{Alb-Hep-MS} \mathrm{suspen-}$ sion. (1) control; (2) $10 \mu \mathrm{g} / \mathrm{ml}$; (3) $1 \mu \mathrm{g} / \mathrm{ml}$; (4) $0.1 \mu \mathrm{g} /$ $\mathrm{ml}$; (5) $0.01 \mu \mathrm{g} / \mathrm{ml}$; (6) $0.001 \mu \mathrm{g} / \mathrm{ml}$.

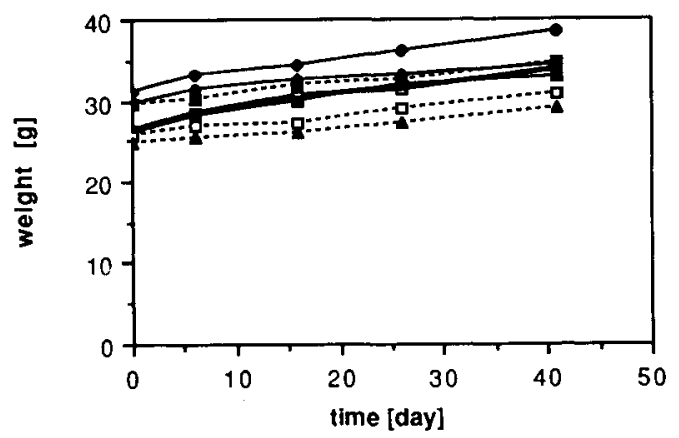

Fig. 9. In vivo toxicity of Alb-Hep-MS; mean body weight of mice after IP injection of microsphere suspension $(n=6$, control: $n=10$ ). $-\square-$ : control; $-\mathbf{-}-: 200 \mathrm{mg} / \mathrm{kg} ;-\square-$-: $100 \mathrm{mg} / \mathrm{kg} ;-1-: 50 \mathrm{mg} / \mathrm{kg} ;-\cdots-\cdots$ $\square$-...-: $12.5 \mathrm{mg} / \mathrm{kg} ;$---.-- 
TABLE 4

Plasma levels of liver-function marker enzymes [IU/1], after Alb-Hep-MS administration into rat liver (2 rats); microspheres were injected at day 1

\begin{tabular}{|c|c|c|c|c|c|c|c|c|c|c|c|c|}
\hline \multirow[t]{3}{*}{ Enzymes $^{a}$} & \multicolumn{12}{|l|}{ Day } \\
\hline & \multicolumn{2}{|l|}{0} & \multicolumn{2}{|l|}{1} & \multicolumn{2}{|l|}{2} & \multicolumn{2}{|l|}{5} & \multicolumn{2}{|l|}{9} & \multicolumn{2}{|l|}{14} \\
\hline & I & II & I & II & I & II & I & II & I & II & I & II \\
\hline Alk. phosph. & 237 & 203 & 180 & 212 & 163 & 541 & 168 & 1205 & 1093 & 2173 & 630 & 757 \\
\hline SGOT & 50 & 78 & 183 & 302 & 79 & 654 & 51 & 42 & 28 & 56 & 49 & 136 \\
\hline SGPT & 34 & 263 & 148 & 263 & 63 & 502 & 19 & 11 & 21 & & 26 & 52 \\
\hline$\gamma-\mathrm{GT}$ & 0 & 1 & 0 & 1 & 0 & 12 & 1 & 7 & 0 & 3 & 1 & 0 \\
\hline $\mathrm{LDH}$ & 385 & 417 & 636 & 709 & 698 & 1230 & 737 & 561 & 290 & 897 & 498 & 641 \\
\hline
\end{tabular}

aAlk. phosph.: alkaline phosphatase; SGOT: serum glutamate oxaloacetate transaminase; SGPT: serum glutamate pyruvate transaminase; $\gamma$-GT: $\gamma$-glutamyl transferase; $\mathrm{LDH}$ : lactate dehydrogenase.

bound to the matrix by the reaction of the adriamycin $\mathrm{NH}_{2}$ groups with the unreacted aldehyde groups. This drug will only be released by the degradation of the matrix. Quenching of the aldehyde groups with glycine before drug loading prevents the covalent coupling of adriamycin to the matrix. It may be expected that quenching of the microspheres will influence both drug loading and drug release. However, from Fig. 5 it can be observed that quenching with glycine has no significant effect on the adriamycin release from $\mathrm{Alb}-\mathrm{MS}$ and $\mathrm{Alb}-\mathrm{Hep}$ Conj-MS. From this it can be concluded that the release of adriamycin is mainly due to unbound and ionically bound drug.

The results from the biocompatibility experiments of the Alb-Hep-MS are shown in Figures 8 and 9 . Figure 9 shows that the unloaded Alb-Hep-MS have no effect on B16 melanotic melanoma cells. The microspheres do not exert toxic effects, nor any growth-stimulating effect in vitro.

Figure 9 shows the results from the in vivo toxicity experiments. It can be seen that the IP administration in mice (even in high amounts of $200 \mathrm{mg} / \mathrm{kg}$ ), has no significant effect on the growth of the mice.
After histological examination no pathological alterations could be observed in any of the treated groups. All organs (liver, spleen, lungs, stomach, kidneys) showed a normal appearance.

After 60 days, incapsulated microspheres could be observed in the $\mathrm{BD}_{2} \mathrm{~F}_{1}$ mice treated with the highest IP dose of Alb-Hep-MS. This indicates that the microspheres are stable. This was not observed in animals treated with lower doses.

After i.v. administration of Alb-Hep-MS into the liver of rats, no significant weight loss of the treated animals versus controls was observed. Table 4 shows that there is a slight increase of the level of liver-function marker enzymes; however, this is probably due to the trauma induced by the operation and the changes are not irreversible, thus indicating that administration of Alb-Hep-MS to the rat liver causes no irreversible damage to the liver as measured by the marker enzyme determination.

Histological examination of the liver showed that after six weeks occluded microspheres still can be found within the portal vein system of the rat liver. A follow-up of these experiments is in progress. 


\section{CONCLUSIONS}

Albumin-heparin microspheres can be prepared by a double crosslinking technique using soluble albumin and heparin and by a two-step process. In this two-step process, first a soluble albumin-heparin conjugate is prepared, which is used for the microsphere preparation in the second step.

Albumin-heparin microspheres can be loaded with adriamycin after the microsphere preparation, giving a high payload as compared to albumin microspheres. The adriamycin release from the Alb-Hep-Conj-MS (two-step process), shows a two-phase release: first there is an initial burst, followed by a slower release. The in vitro and in vivo experiments suggest the AlbHep-MS are non-toxic. Also no inflammatory reactions were induced by the Alb-Hep-MS after IP administration. Administration of a dose of $6.0 \mathrm{mg} / \mathrm{kg}$ into the liver of rats does not cause any irreversible damage to the liver function. The in vivo biodegradation studies show that the microspheres are still present in the liver after six weeks.

\section{ACKNOWLEDGEMENTS}

Thanks are due to NWO (The Netherlands Organization for Scientific Research), Theratech Inc., SLC, Utah, and to Prof. Dr. F. Arcamone, (Pharmitalia).

\section{REFERENCES}

1 A.E. Senyei, C.F. Driscoll and K.J. Widder, Biophysical drug targeting: Magnetically responsive albumin microspheres, Meth. Enzymol., 112 (1985) 56-67.

2 W.E. Longo and E.P. Goldberg, Hydrophilic albumin microspheres, Meth. Enzymol., 112 (1985) 18-27.

3 P.K. Gupta, J.M. Gallo, C.T. Hung and D.G. Perrier, Influence of stabilization temperature on the entrapment of adriamycin in albumin microspheres, Drug Dev. Ind. Pharm., 13 (1987) 1471-1482.
4 C.S. MacArdle, H. Lewi, D. Hansell, D.J. Kerr, J. McKillop and N. Willmott, Cytotoxic-loaded albumin microspheres: A novel approach to regional chemotherapy, Br. J. Surg., 75 (1988) 132-134.

5 P.A. Kramer, Albumin microspheres as vehicles for achieving specificity in drug delivery, J. Pharm. Sci., 63 (1974) 1646-1647.

6 M.F.A. Goosen, Y.F. Leung, G.M. O'Shea, S. Clou and A.M. Sun, Slow release of insulin from a biodegradable matrix implanted in diabetic rats, Diabetes, 32 (1983) 478-481.

7 D.J. Burgess, S.S. Davis and E. Tomlinson, Potential use of albumin microspheres as a drug delivery system. I. Preparation and in vivo release of steroids, Int. J. Pharm., 39 (1987) 129-136.

8 A.F. Yapel, Albumin microspheres: Heat and chemical stabilization, Meth. Enzymol., 112 (1985) 3-18.

9 S.S. Davis, S.N. Mills and E. Tomlinson, Chemically cross-linked albumin microspheres for the controlled release of incorporated rose bengal after intramuscular injection into rabbits, J. Controlled Release, 4 (1987) 293-302.

10 S. Fujimoto, M. Miyazaki, F. Endoh, O. Takahashi, R.D. Shrestha, K. Okui, Y. Morimoto and K. Terao, Effects of intra-arterially infused biodegradable microspheres containing mitomycin $\mathrm{C}$, Cancer, 55 (1985) 522-526.

11 H.P.J.M. Noteborn and J.G. McVie, Chemoembolization in regional chemotherapy, in: L. Domellöf (Ed.), Drug Delivery in Cancer Treatment, ESO Monographs, Springer Verlag, Berlin-New York (in press).

12 E. Tomlinson, J.J. Burger, E.M.A. Schoonderwoerd and J.G. McVie, Human serum albumin microspheres for intraarterial drug targeting of cytostatic compounds. Pharmaceutical aspects and release characteristics, in: S.S. Davis, L. Illum, J.G. McVie and E. Tomlinson (Eds.), Microspheres and Drug Therapy. Pharmaceutical, Immunological and Medical Aspects, Elsevier, Amsterdam, 1984, pp. 75-89.

13 N. Willmott, Y. Chen and A.T. Florence, Haemoglobin, transferrin and albumin/polyaspartic acid microspheres as carriers for the cytotoxic drug adriamycin. II. In vitro drug release rate, J. Controlled Release, 8 (1988) 103-109.

14 P.K. Gupta, C.T. Hung and D.G. Perrier, Albumin microspheres. II. Effect of stabilization temperature on the release of adriamycin, Int. J. Pharm., 33 (1986) 147-153.

15 W.E. Longo, H. Iwata, T. Lindheimer and E.P. Goldberg, Preparation and drug release properties of albumin-polyglutamic acid-adriamycin microspheres, $\mathrm{Po-}$ lym. Prepr., 24 (1983) 56-57.

16 N. Willmott, Y. Chen and A.T. Florence, Haemoglobin, transferrin and albumin/polyaspartic acid microspheres as carriers for the cytotoxic drug adriamycin. 
I. Ultrastuctural appearance and drug content, J. Controlled Release, 8 (1988) 93-101.

17 W.E. Hennink, J. Feijen, C.D. Ebert and S.W. Kim, Covalently bound conjugates of albumin and heparin: Synthesis, fractionation and characterization, Thromb. Res., 29 (1983) 1-13.

18 E. Cofrancesco, A. Vigo and E. Poglinai, Antiheparin activity of adriamycin, Thromb. Res., 18 (1980) 143746.
19 L.B. Jacques and A. Wollin, A modified method for the colorimetric determination of heparin, Can. J. Phys. Pharm., 45 (1967) 787-794.

20 J. Goa, A micro biuret method for protein determination. Determination of total protein in cerebrospinal fluid, Scand. J. Clin. Lab. Invest., 5 (1953) 218222.

21 A. Sawaya, J.-P. Benoit and S. Benita, Binding mechanism of doxorubicin in ion-exchange albumin microcapsules, J. Pharm. Sci., 76 (1987) 475-480. 